\title{
Study of processes of artificial freezing and thawing of soils when developing a model of energy-efficient radiation- convection setup
}

\author{
Anatoly Velsovskij ${ }^{1}$, Liliya Mukhametova ${ }^{2}$, Anton Sinitsyn $^{1}$ and Denis Karpov ${ }^{1}$ \\ ${ }^{1}$ Vologda State University, LeninaStr.. 15, 160000, Russia \\ ${ }^{2}$ Kazan State Power Engineering University, Kazan, Russia
}

\begin{abstract}
This paper considers one stage of development of a new power plant for thawing frozen soil during emergency repairs. It includes experimental study of temperature conditions for freezing and artificial thawing of various types of soils in field and laboratory conditions. The main results of laboratory research are presented. The operation process of an industrial prototype of power plant is modelled on a test bench using analogues of radiation-convective heat generators. The obtained calculated and experimental characteristics of artificial thawing of frozen soil by a surface radiation-convective method will allow one to calculate the thermal power of a power plant, and to carry out its design and thermal calculation.
\end{abstract}

\section{Introduction}

The search for new technological solutions and soil preparation systems during repair, construction and emergency operations is an important task in our country due to its harsh climatic conditions. The increased mechanical strength of frozen soils prevents their excavation by conventional technical means, which necessitates the preliminary preparation of such soils. The following basic methods of soil preparation in winter conditions are used: thawing with subsequent excavation of thawed soil, preliminary mechanical loosening and excavation of frozen soil. Mechanized methods are currently the most common, but the use of special means of loosening or cutting into separate pieces in complex urban underground economy is difficult, and sometimes impossible for technical requirements and safety reasons. In urban conditions, the problem of excavation of frozen soils is dealt by, first of all, emergency, communal and energy supplying services and organizations. A large number of emergency situations in winter are associated with ruptures of pipelines for various purposes. The recovery time of site directly depends on the speed of opening the damaged pipeline by the repair team. Another important aspect of the problem raised above is soil preparation before construction - a task for builders conducting work in winter. The use of special means of soil loosening or cutting does not enable to use the mixture without a sufficient amount of thawed soil for construction of embankments, backfilling of trenches and sinuses of foundation pits due to the impossibility of high-quality compaction, since it leads to soil subsidence after thawing. In such conditions, the use of alternative methods of soil preparation during repair, construction and emergency works expands the technical capabilities of the organization and allows ensuring the work efficiency. These tasks can be solved using soil thawing.

The performed literature and patent review showed a variety of methods for thawing frozen soils. They are classified according to the used heat source (electricity, steam, gas, fuel oil, coke, hot slag, etc.) and operation principle (thermal, chemical, etc.)

General scientific principles for the design of engineering systems and devices in frozen soils are formulated in the works of N.A. Tsytovich [1], Pavlov A.R. [2], Sagala T.A. and Kologrivov M.M. [3]. Nakano, Y., Brown, J., [4], Harlan, R. L. [5], Guymon, G. L. and J. N. Luthin [6] dealt with the problems of heat and mass transfer in frozen soils.

Despite the fact that significant scientific forces are being attracted to solve this problem in the world, in practice there still remain a number of issues related to the design, calculation, execution and safe operation of devices and mechanisms for the development of frozen soils.

The existing methods are of limited application due to high energy costs and long time required for heating (from five hours or more to several days), or they are unacceptable for safety reasons for certain types of work (excavation of gas, electric networks, etc.).

The development of an effective and uninterrupted power supply system for low outdoor temperatures was previously considered in [7]. This article is focused on the solution to the problem of eliminating accidents in case of failure of a particular section of engineering communications.

The need to create a small-sized setup for thawing frozen soils appeared as a result of professional cooperation of the university and the city emergency- 
Table 1. Characteristics of the developed setup.

\begin{tabular}{|c|l|c|}
\hline No. & \multicolumn{1}{|c|}{ Characteristics } & Value \\
\hline 1 & Operation principle & Radiation-convective heat transfer \\
\hline 2 & Fuel type & Natural gas, propane-butane \\
\hline 3 & Thawing time, $\mathrm{h}$ & Not more than 4 \\
\hline 4 & Maximum thawing depth, $\mathrm{m}$ & Not less than 1.5 \\
\hline 5 & Installation size, $\mathrm{m}$ & $1 \times 1.5 \times 0.4$ \\
\hline 6 & Allowable weight, $\mathrm{kg}$ & Not more than 90 \\
\hline 7 & Operating personnel, man & 2 \\
\hline
\end{tabular}

maintenance and public utilities, which needed such a device. The importance of task for creating a new setup was determined by the unsolved problem of rapid development of frozen soil in cramped conditions of complex urban underground utilities. In such conditions it is impossible to use conventional technical means of loosening or cutting frozen soils due to technical requirements and safety reasons [8].

Currently, there are a large number of methods for calculation heating of frozen soils, but the model proposed in [9] is the most acceptable. In accordance with [10], the thermal performance of the installation for thawing sand building material was calculated according to empirical formulas used in the calculations for construction of facilities in permafrost areas.

\section{Problem statement}

To determine the requirements and parameters of setup being developed, the exploratory studies were carried out aimed at identifying its main technical and operational characteristics and their analysis (table 1). The radiationconvective thawing principle was chosen, and gas fuel was the main energy source.

The time required to thaw the soil to a given depth, shown in table 1, was determined on the basis of requirements for emergency repairs by various repair services in one work shift. In order to ensure soil thawing within the allotted time interval (not more than 4 hours), it was necessary to determine the power of setup being created.

A number of methods were applied to identify the required power and experimentally confirm the calculated parameters by conducting a series of tests on freezing and thawing various types of soils. Sand of medium size and light loam were used as the main soils. For them, physical properties and classification indicators were determined in accordance with the requirements of regulatory documents. To create conditions for experiment conducting in close to field a)

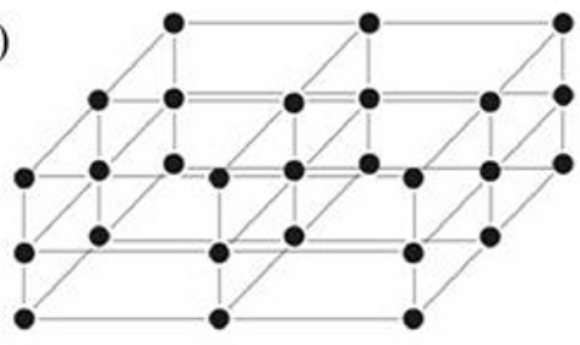

c)

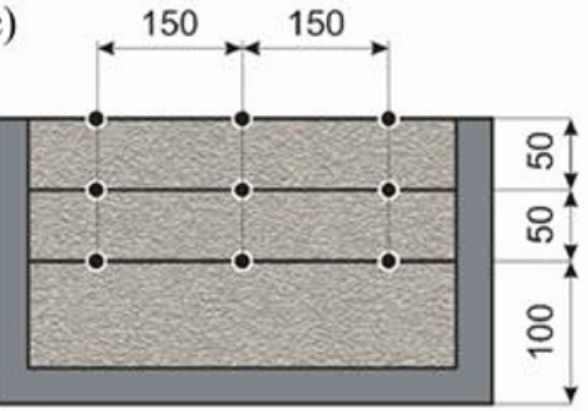

b)

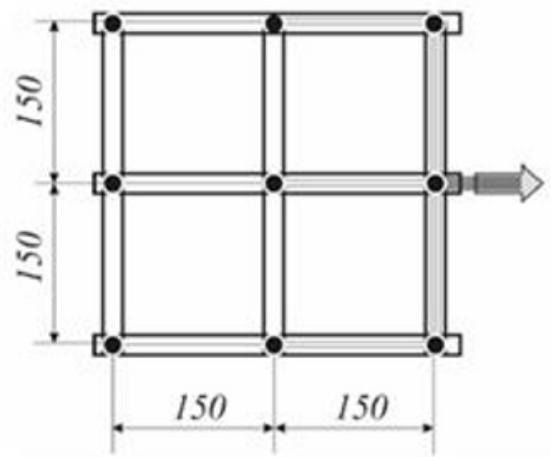

d)

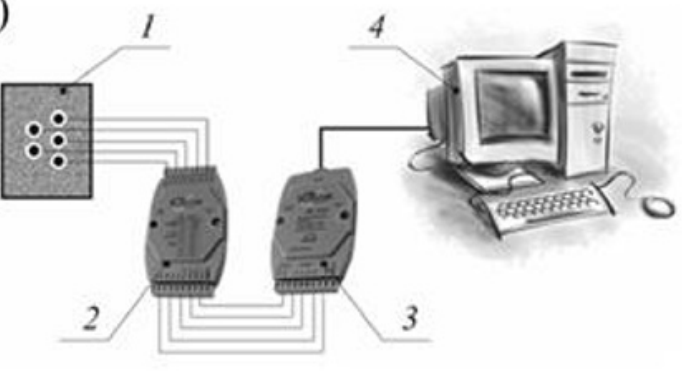

Fig. 1. Preparation for an experiment on soil freezing: a) Matrix of thermocouple location points; b) Frame for accurate placement of sensors in the plan; c) Mold with compacted soil and location of thermocouples in the profile; d) Temperature measurement scheme (1 - mold with soil and installed temperature sensors, 2,3 - analogue block-digital converter, 4 computer), dimensions are shown in millimeters. 
a)

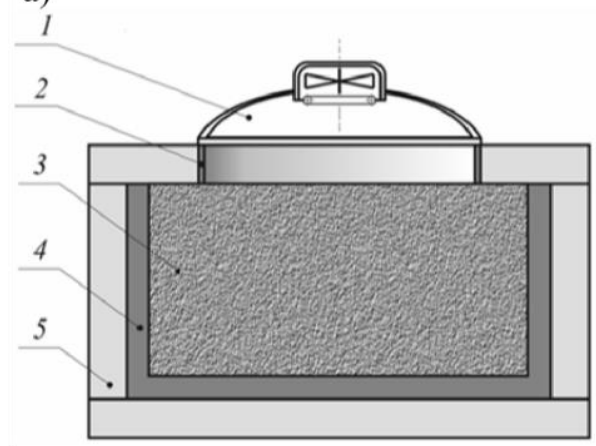

b)

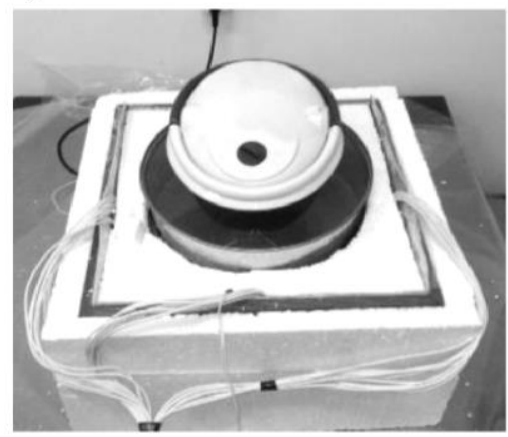

Fig. 2. Scheme of experimental setup: a) Scheme of setup, b) Photograph of the laboratory setup, 1 - Radiation-convection device, 2 - Metal ring, 3 - Frozen soil, 4 - Mold for soil, 5 - Thermal insulation.

conditions, the maximum density, optimal humidity and density in natural occurrence at a depth of up to $1.5 \mathrm{~m}$ were determined.

\section{Methods}

The methodology of experiment on freezing molds with soil included:

1) Preparation of the necessary elements (molds for soil, grids with thermocouples for measuring temperature fields, block of converter equipment and computer for recording readings from thermocouples);

2) Soil preparation (drying to constant weight, mixing to obtain a homogeneous environment, moistening, laying and layer-by-layer compaction in the prepared mold);

3) Preparation of a stationary cold store (type KHN1) for testing, setup of freezable molds with soil and setting the temperature regime (from -4 to $-6{ }^{\circ} \mathrm{C}$ ) for uniform freezing.

The temperature change in soil during freezing and subsequent thawing was monitored similar to [11-12] using temperature sensors, location matrix of which is shown in Figure 1, a. The measurements were carried out in three horizons; nine temperature sensors were installed in each of them. To achieve accurate placement of temperature sensors, they were fixed on a specially designed frame, the view of which and dimensions in plan and profile are shown in Figures 1, b, c.

As in [7], chromel-alumel junctions of thermocouples connected to an analogue-to-digital converter were used as temperature sensors during the experiment. The RS 232 cable was used to connect the analogue-to-digital converter with PC, which was used to display the freezing-thawing processes in real time (Figure 1, d).

During experiments, the mold with frozen soil was covered with heat insulation from the sides and from the bottom to prevent their heating and to create conditions for thawing from above (Figure 2).

\section{Results}

The experiment consisted of preliminary freezing the soil, and its subsequent artificial thawing. Every two seconds the readings of temperature sensors were registered, and the depth of soil freezing (thawing) was measured using the metering probe. The measured freezing depths for sandy soil are presented in Figure 3.

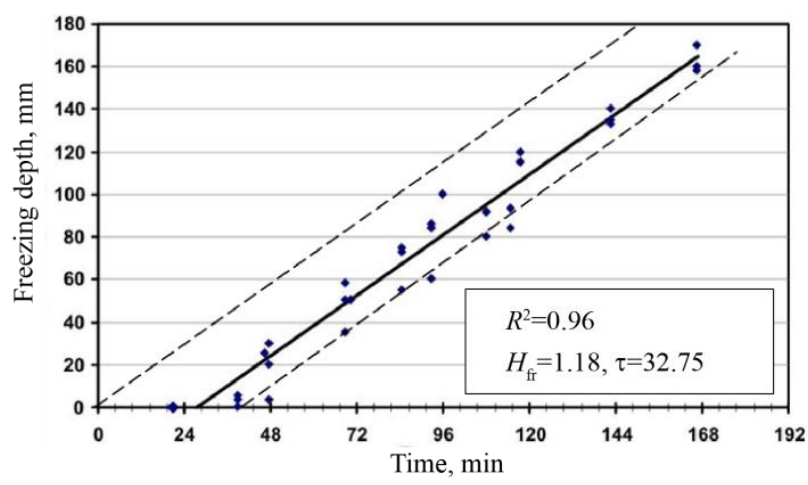

Fig. 3. Change of freezing depth in time.

The experiment was carried out with the following characteristics of artificial source of thermal energy:

- Type of heater - electric heater;

- Consumed electrical power - $1300 \mathrm{~W}$;

- The established temperature regime $-250{ }^{\circ} \mathrm{C}$;

- Diameter of thawing zone - $330 \mathrm{~mm}$

Thawing was performed for a sandy soil of $1.6 \mathrm{~g} / \mathrm{cm}^{3}$ density and of $30 \%$ humidity at the initial material temperature of $-1.8{ }^{\circ} \mathrm{C}$. The condition of heating the frozen soil by the radiation-convective setup was experimentally studied in field and laboratory conditions. Comparison of the obtained results is shown in Figure 4.

The relationship between the thawing depth $H_{\text {th }}$ and the time of thermal energy supply $\tau$ can be expressed by the following empirical expression:

$$
H_{\text {th }}=K \cdot \tau^{0.5} \text {, }
$$




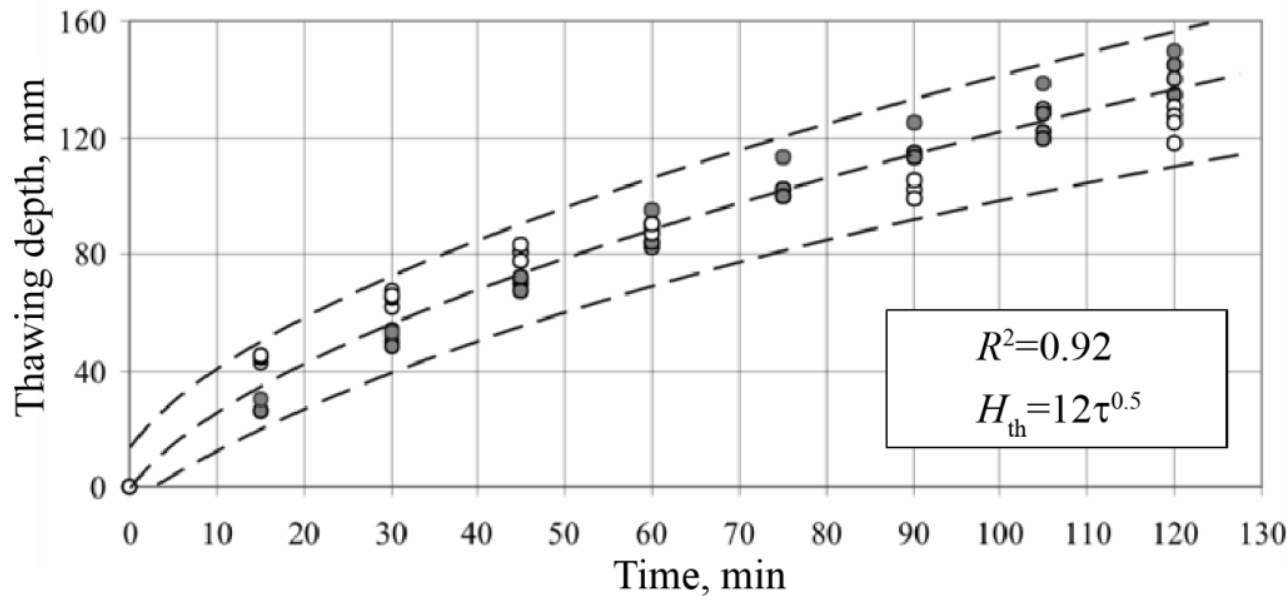

Fig. 4. Relationship between the thawing depth (dark dots are experimental data obtained in field conditions, light dots are experimental data obtained in the laboratory).

where $K=f\left(K_{1}, K_{2}, . . K_{N}\right) \quad$ is the coefficient depending on the soil type, the power of heat source, the condition of thawing and removal of thawed soil, environmental conditions, etc .; $\tau$ is time of heat energy supply,.

Calculations were performed according to the indicated empirical dependence and according to the engineering method for calculating the thickness of melt zone of dispersed material as a function of its thawing time. Comparison of the calculation results showed sufficient accuracy of the proposed dependence.

The conditions for removing the thawed part of frozen soil have a strong influence on thawing rate of frozen soil. The generalizing experimental dependences of depth of artificial thawing of frozen soil change over time were obtained for energy expenditures of $1300 \mathrm{~W}$ and thawing area of $85 \cdot 10^{-3} \mathrm{~m}^{2}$, and shown in Figure 5 .

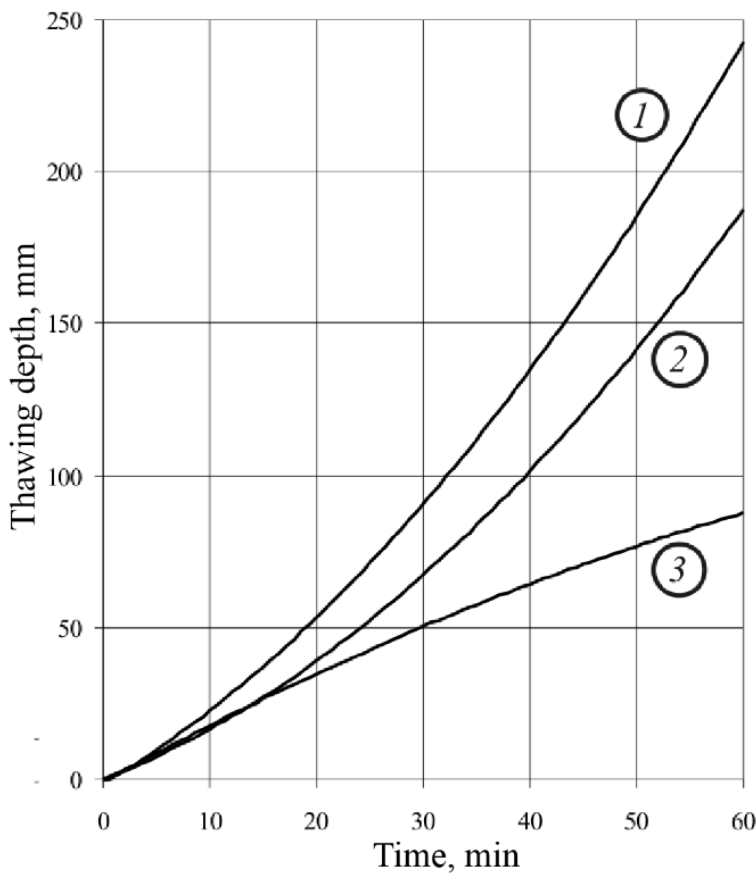

Fig. 5. Generalizing experimental dependence of depth of artificial thawing of frozen soil change over time: 1 permanent removal of thawed part of frozen soil; 2 - periodic removal of thawed part of frozen soil; 3 - without removing the thawed part of frozen soil.

From Figure 5 it can be seen that the rate and, accordingly, the depth of thawing depends on the conditions for removal of thawed soil. With permanent removal of soil (every $5 \mathrm{~min}$ ), the depth of thawing is 3 times greater than when thawing is performed without removing it. With periodic soil removal (every $15 \mathrm{~min}$ ), the thawing depth is 2 times greater than thawing is performed without removing it. The ratio of thawing depth at constant and periodic soil removal was 1.5 times. This must be taken into account when developing technology for thawing frozen soil.

The installation is an integrated mobile device (Figure 6), divided into three separate but interconnected 
Table 2. Comparative characteristics of technical means.

\begin{tabular}{|c|l|c|c|c|}
\hline No. & \multicolumn{1}{|c|}{ Characteristics } & $\begin{array}{c}\text { The developed } \\
\text { device }\end{array}$ & $\begin{array}{c}\text { Thermoelectric mat } \\
\text { TERMOMAT }\end{array}$ & $\begin{array}{c}\text { The device for heating soil and concrete } \\
\text { E700M (WACKER NEUSON) }\end{array}$ \\
\hline 1 & Device power, $\mathrm{W} / \mathrm{m}^{2}$ & $\mathbf{7 5 0 0}$ & 340 & 180 \\
\hline 2 & $\begin{array}{l}\text { Thawing time to a depth } \\
\text { of } 0.5 \mathrm{~m}, \text { hour }\end{array}$ & $\mathbf{1 5}$ & 30 & 24 \\
\hline 3 & $\begin{array}{l}\text { Costs for thawing, } \\
\text { rub. } / \mathrm{h} \cdot \mathrm{m}^{2}\end{array}$ & $\mathbf{4 , 9}$ & 23 & 147 \\
\hline 4 & Heating temperature, ${ }^{\circ} \mathrm{C}$ & $\mathbf{2 5 0}$ & 70 & 32 \\
\hline 5 & $\begin{array}{l}\text { Dimensions, } \mathrm{mm} \times \mathrm{mm} \\
\text { x mm }\end{array}$ & $1200 \times 1600 \times 700$ & $\mathbf{5 5 0 \times 2 7 4 0 \times 1 5}$ & $3390 \times 1500 \times 1970$ \\
\hline 6 & Mass, $\mathrm{kg}$ & 110 & $\mathbf{2 0}$ & 3346 \\
\hline
\end{tabular}

sections: working, electric and technical. It includes a burner, a smoke pipe, a smoke exhaust, a reflective screen, a fan, a heat exchanger and an air heater. The fan is operated by an electric motor connected to an electric battery. The electric motor and the battery are located in the electric motor section. The burner, smoke tube, smoke exhaust, air heater and heat exchanger are located in the technical section, the reflective screen is in the working section.

Thawing of frozen soils by a surface artificial method is achieved through the use of a device for radiationconvective heating of working bodies. The invention is consisted of the following main equipment: a burner device, which is used to mix fuel and air with formation of a fuel-air mixture and to maintain its stable combustion; a smoke tube in which the flame is developed and flue gases are moved, as well as a pipe is heated to create radiation -convective heat transfer from the pipe to the environment; a smoke exhauster that stimulates motion of flue gases from the burner along the entire length of the smoke pipe to its outlet to the air heater. In the air heater, heat is exchanged between the exhaust flue gases and cold air, as a result of which the source air is heated to the required temperature to increase the efficiency of burning the mixture. A reflective screen is located in the upper part of the working space of the apparatus above the smoke tubes and fan. To create radiation-convective heat transfer, a fan is placed in the apparatus, which performs motion of gaseous heated medium in the working space area, limited by a reflective screen and heated material. The fan operation is organized by an electric motor connected to an electric battery.

Efficiency is ensured by optimizing the location of the main elements of the installation and by combination of convective and radiation heat transfer methods.

To evaluate the efficiency of the obtained results, we compared the two closest analogues to the developed technical means for soil thawing: thermoelectric mat TERMOMAT and the WACKER NEUSON E700M device - a unit for thawing soil to a depth of 1.5 meters and for service of concrete, running on liquid fuel. Table 2 shows the comparison of the listed technical means. The highlighted values show the advantages of the considered technical tool over others.

\section{Conclusions}

The obtained calculated and experimental dependences of artificial thawing of frozen soil by a surface radiationconvective method will allow us to calculate the thermal power of the setup, perform its design calculation and develop a working test sample.

The proposed installation is more efficient in terms of specific heating power per $1 \mathrm{~m} 2$ of soil; thawing time to a depth of $0.5 \mathrm{~m}$; costs for thawing expressed in monetary terms - rub./h॰m2, as well as heating temperature. Thermomat is more attractive from the point of view of movement and transportation as it has low dimensions and weight, however, taking into
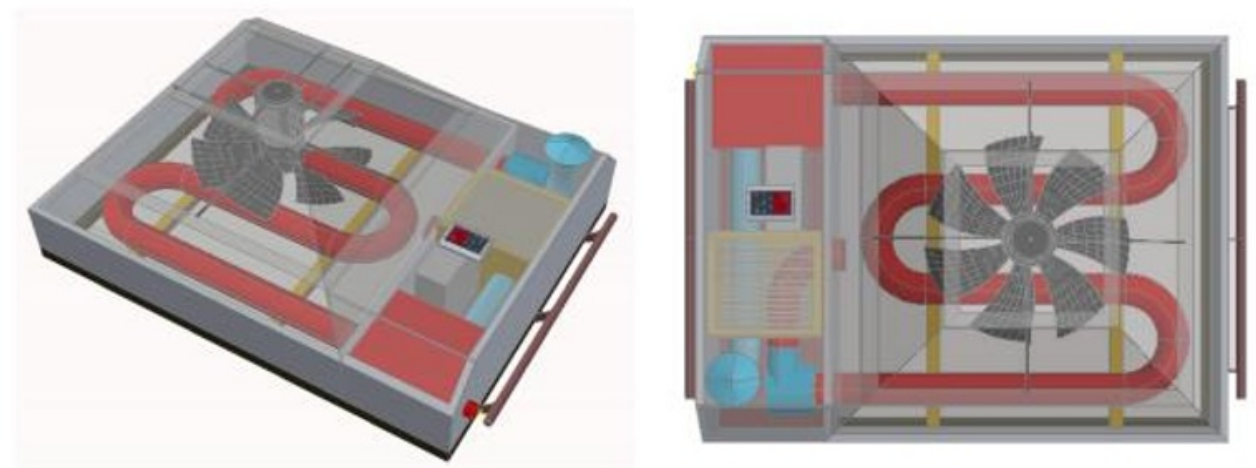

Fig. 6. Prototype of a mobile radiation-convection device. General view. 
account its low efficiency during thawing (about 30 hours), these advantages are not so important. In view of the fact that the second analogue - the device for heating the soil and concrete E700M - is designed for large heating areas (up to $400 \mathrm{~m} 2$ ), it is inefficient and unreasonable for our conditions.

Thus, it is proved that the developed installation is efficient and competitive as compared with the existing technical means.

In addition, the following main features of the proposed installation are highlighted:

- Construction and design have no analogues in the modern market of technical equipment for repair and construction works;

- It has the minimum time for warming up frozen soil in comparison with the existing installations;

- Low specific energy consumption of the installation and the combined heat transfer method provide high installation efficiency;

- The mobility and compactness of the installation enables it transportation in a truck and carrying out work by a team in the amount of two people under any conditions of tightness of the urban landscape;

- The flexibility of regulating the heating capacity of the installation ensures its use by thawing building materials and heating building structures for any purpose;

- An energy-efficient combination of installation elements and a thermo-insulated housing allow repair and construction work in any climatic conditions.

\section{References}

[1] N.A. Tsytovich, Mechanics of frozen soils ( Moscow: Higher School, 446, 1973).

[2] A.R. Pavlov, Mathematical modeling of heat and mass transfer processes during phase transitions: textbook (Yakutsk, 55, 2001).

[3] T.A. Sagala, M.M. Kologrivov, The use of mathematical models of non-stationary thermal conductivity with a phase transition of component in the calculations of defrosting bulk cargo, Refrigeration equipment and technology 3, 46-51 (2008).

[4] Y. Nakano, J. Brown, Effects of a freezing zone of finite width on the thermal regime of soils, Water Resour. Res. 7, 1226-1233 (1971).

[5] R.L. Harlan, Analysis of coupled heat-fluid transport in partially frozen soil, Water Resour. Res. 9, 1314-1323 (1973).

[6] G.L. Guymon, J.N. Luthin, A coupled heat and moisture transport model for arctic soils, Water Resour. Res. 10, 995-1001 (1974).

[7] A. Sinitsyn, A. Mihin, D. Zaripova, Development of a mobile power plant for thawing frozen soils, IOP Conference Series: Earth and Environmental Science 337, 1, 012064 (2019).

[8] A. Sinitsyn, Device for Thawing of Frozen Soils, Life Science Journal 10, 4, 1651-1656 (2013).

[9] A.A. Sinitsyn, D.A. Belyanskii, The Development and Experience in Using a Series of Celsius Sensors for Monitoring the Temperature of the
Working Body in a System for Controlling the Drying of Ceramic Articles, Measurement Techniques 56, 11, 1269-1273 (2014).

[10] A.A. Sinitsyn, D.A. Belyanskiy, I.A. Sukhanov, Development of New Sensors for the Temperature Control of a Working Body, Life Science Journal 10, 4, 1057-1061 (2013).

[11] M.V. Pavlov, D.F. Karpov, A.A. Sinitsyn, Experimental Research of the Thermal Balance of Loose Disperse Materials Exemplified by Milled Peat Exposed to Infrared Heating. Vestnik MGSU, Proceedings of Moscow State University of Civil Engineering 5, 114119 (2012).

[12] M.V. Pavlov, D.F. Karpov, A.A. Sinitsyn, Solution to the Boundary Problem of Heat and Water Transmission in a Layer of a Loose Disperse Material Exemplified by Milled Peat Exposed to Infrared Heating. Vestnik MGSU, Proceedings of Moscow State University of Civil Engineering 6, 92-98 (2012). 